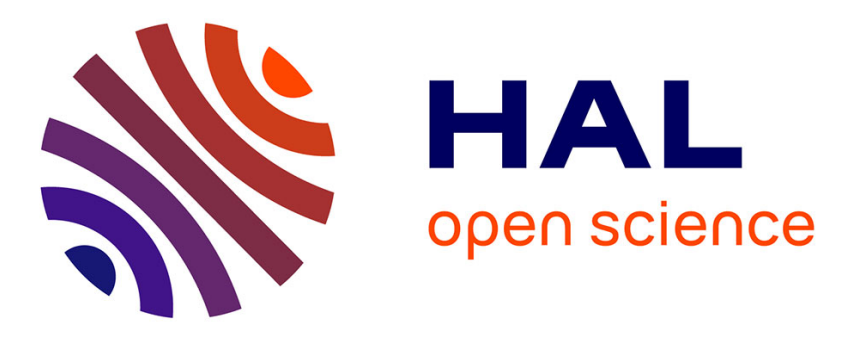

\title{
Cobalt-Catalyzed C(sp2)-CN Bond Activation: Cross-Electrophile Coupling for Biaryl Formation and Mechanistic Insight
}

Céline Dorval, Maxime Tricoire, Jeanne-Marie Begouin, Vincent Gandon, Corinne Gosmini

\section{To cite this version:}

Céline Dorval, Maxime Tricoire, Jeanne-Marie Begouin, Vincent Gandon, Corinne Gosmini. CobaltCatalyzed C(sp2)-CN Bond Activation: Cross-Electrophile Coupling for Biaryl Formation and Mechanistic Insight. ACS Catalysis, 2020, 10 (21), pp.12819 - 12827. 10.1021/acscatal.0c03903 . hal03026541

\section{HAL Id: hal-03026541 https://hal.science/hal-03026541}

Submitted on 20 Aug 2021

HAL is a multi-disciplinary open access archive for the deposit and dissemination of scientific research documents, whether they are published or not. The documents may come from teaching and research institutions in France or abroad, or from public or private research centers.
L'archive ouverte pluridisciplinaire HAL, est destinée au dépôt et à la diffusion de documents scientifiques de niveau recherche, publiés ou non, émanant des établissements d'enseignement et de recherche français ou étrangers, des laboratoires publics ou privés. 


\title{
Cobalt-Catalyzed $\mathrm{C}\left(s p^{2}\right)-\mathrm{CN}$ Bond Activation: Cross- Electrophile Coupling for Biaryl Formation and Mechanistic Insight
}

\author{
Céline Dorval, ${ }^{a}$ Maxime Tricoire, ${ }^{a}$ Jeanne-Marie Begouin, ${ }^{a}$ Vincent Gandon, ${ }^{* a, b}$ and Corinne
}

\author{
Gosmini*a
}

a Laboratoire de Chimie Moléculaire, CNRS UMR 9168, École polytechnique, Institut Polytechnique de Paris, Route de Saclay, 91128 Palaiseau Cedex, France

b Institut de Chimie Moléculaire et des Matériaux d'Orsay (ICMMO), CNRS UMR 8182, Université Paris-Saclay, Bâtiment 420, 91405 Orsay Cedex, France

\begin{abstract}
Herein, we report a cross-electrophile coupling of benzonitrile derivatives and aryl halides with a simple cobalt-based catalytic system under mild conditions to form biaryl compounds. Even though the cobalt catalyst is able to activate the $\mathrm{C}\left(s p^{2}\right)-\mathrm{CN}$ bond alone, the use of the $\mathrm{AlMe}_{3}$ Lewis acid enhances the reactivity of benzonitriles and improves the cross-selectivity with barely any influence on the functional group compatibility. X-Ray structure determination of an original low-valent cobalt species combined with catalytic and stoichiometric reactions reveal a catalytically active cobalt(I) species towards the aryl halide partner. On the other hand, experimental insights, including cyclic voltammetry experiments, suggest the involvement of a cobalt complex of a lower oxidation state to activate the benzonitrile derivative. Finally, DFT calculations support the proposed mechanistic cycle involving two low-valent cobalt species of different oxidation states to perform the reaction.
\end{abstract}

KEYWORDS: cobalt, catalysis, benzonitriles , reductive cross-coupling, biaryl, cross-electrophile coupling

\section{Introduction}

Benefiting from more than 50 years of research, noble metals have a longstanding record in the field of homogeneous catalysis. ${ }^{1}$ However, the depletion of their resources, ${ }^{2}$ implying high costs and sustainability issues, ${ }^{3}$ has stimulated the search for non-noble metals surrogates. These studies have revealed unsuspected reactivities, ${ }^{4}$ and notably led to the development of first-row transition metal-catalyzed cross-electrophile coupling reactions that have emerged as a powerful tool to create carbon-carbon (C-C) bonds in particular for biaryl formation. ${ }^{5}$ In contrast with the traditional redox-neutral couplings, crosselectrophile couplings require no preliminary preparation of a stoichiometric nucleophilic organometallic species, which makes them more straightforward and often allows better functional group tolerance. First mainly based on the activation of two halide derivatives, ${ }^{5}$ the limited availability and difficult synthesis of such substrates have led chemists to consider other types of electrophiles to perform such reactions. ${ }^{6}$

In this area, one of the biggest challenges remains the activation of thermodynamically stable $\mathrm{C}-\mathrm{C}$ bonds. In particular, even though great improvements have been made recently, metal-catalyzed activation of unstrained $\mathrm{C}-\mathrm{C}$ bond $s^{7,8}$ is still largely underdeveloped. ${ }^{7,9}$ Among them, the activation of $\mathrm{C}\left(s p^{2}\right)-\mathrm{CN}$ bond is believed to have a great potential to develop original synthetic methodologies. ${ }^{10}$ Indeed, benzonitriles are relatively abundant ${ }^{11}$ and more and more readily accessible from ubiquitous functional groups. ${ }^{12}$ They are also quite stable under various reaction conditions, which makes them appealing for late-stage cross-coupling reactions. Therefore, despite its high bond dissociation energy $\left(\mathrm{PhCN} \sim 132 \mathrm{kcal}^{\mathrm{mol}}{ }^{-1}\right){ }^{13}$ chemists have been attracted to activate this unstrained $\mathrm{C}\left(s p^{2}\right)-\mathrm{CN}$ bond with transition metals.

Stoichiometric activation studies ${ }^{14}$ with different metals have revealed two major activation pathways (Scheme 1a). The first pathway involves mainly electron-rich metal(0) complexes which insert via oxidative addition into the $\mathrm{C}\left(s p^{2}\right)-\mathrm{CN}$ bond (pathway $\left.\mathbf{A}\right) .{ }^{14,15}$ The second activation mode relies on the assistance of silicon, in which the prior formation of a silylated complex is followed by the migratory insertion of the nitrile into the M-Si bond (pathway B). ${ }^{14,16}$ Among metals reported to activate $\mathrm{C}\left(s p^{2}\right)-\mathrm{CN}$ bonds, $\mathrm{Ni}, \mathrm{Rh}$ and $\mathrm{Pd}$ have been mainly applied in catalysis. $7,9 b, 17$ Notably, in cross-coupling reactions, ${ }^{18}$ apart from a particular cross-coupling between benzonitrile and azole derivatives, ${ }^{19}$ thus, necessitating to employ a nickel(0)/alkyl phosphine catalyst to be able to activate the $\mathrm{C}\left(s p^{2}\right)-\mathrm{CN}$ bond via pathway $\mathbf{A}$, biaryl formation from benzonitriles has been reported using nickel catalyst with organometallic coupling partners ${ }^{20}$ such as aryl Grignard reagents, ${ }^{21,22}$ arylboronic esters ${ }^{23}$ as well as arylmanganese compounds (Scheme 1b). ${ }^{24}$ The use of such organometallic species makes easy the reduction of nickel(II)/alkyl phosphines pre-catalysts into nickel(0) active species, which can then insert into the $\mathrm{C}\left(s p^{2}\right)-\mathrm{CN}$ bond according to pathway A. However, the use of nucleophilic species might sometimes be incompatible with late-stage derivatization 
and sensitive functional groups. Chatani et $a l^{25}$ disclosed a rhodium-catalyzed assisted with silicon (pathway B) cross-electrophile coupling from benzonitrile derivatives (Scheme 1c) which could overcome these drawbacks. Nevertheless, high temperature and restriction to intramolecular arylation reduces its applicability.

Scheme 1. (a) Different metal-catalyzed activation pathways. (b) Redox-neutral coupling with benzonitrile derivatives and nucleophilic organometallic reagents. (c) Intramolecular cross-electrophile coupling from benzonitrile derivatives. (d) Intermolecular cross-electrophile coupling from benzonitrile derivatives (this work).

(a) Activation pathways

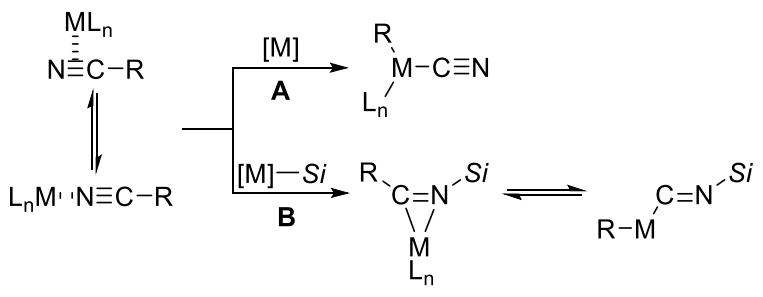

(b) Redox-neutral coupling (Miller, Shi, Wang)

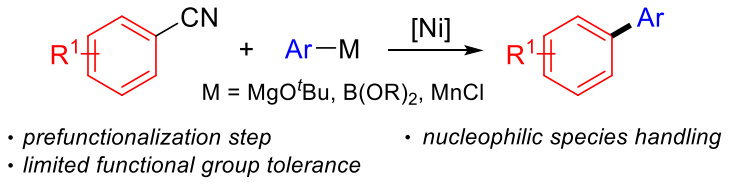

(c) Intramolecular cross-electrophile coupling (Chatani)

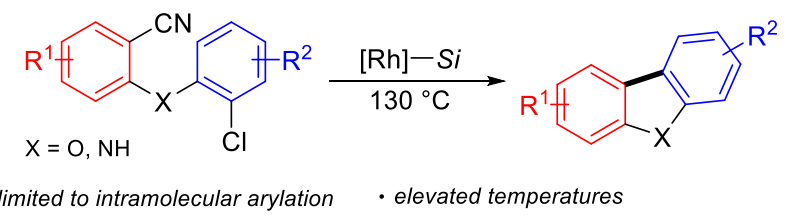

(d) Intermolecular cross-electrophile coupling (this work)

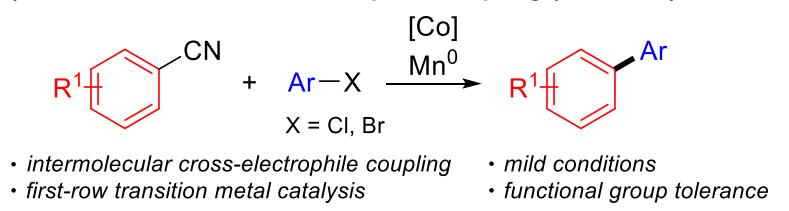

Cobalt complexes have already shown to be efficient catalysts to perform cross-electrophile coupling reactions. ${ }^{5 b, 26,27}$ Moreover, we and others have revealed the great ability of cobalt complexes to perform cross-coupling reactions of partners other than halide derivatives. ${ }^{28}$ Therefore, as part of our continuous effort to develop efficient couplings from more stable and available halide surrogates, we disclose herein an attractive cobalt-catalyzed intermolecular cross-electrophile coupling to form biaryls from benzonitrile derivatives under mild conditions (Scheme 1d). The major challenge of such intermolecular coupling is to favor cross-selectivity from two electrophilic starting materials displaying the same reactivity towards transition metals. ${ }^{5}$ In the present methodology, the difficult activation of benzonitriles makes this challenge even bigger. To the best of our knowledge, this is the first example of catalytic cross-coupling reactions involving $\mathrm{C}-\mathrm{CN}$ activation with cobalt. ${ }^{29}$

\section{Results and Discussion}

Optimization study. The optimized conditions of the reaction are shown in Table 1 . Reaction of benzonitrile (1) and methyl 4-chlorobenzoate (2) in the presence of preformed $\mathrm{CoBr}_{2} \mathrm{Bipy}_{2}$ (20 mol\%) (see S4.) and $\mathrm{Mn}$ powder (4.0 equiv.) in DMF at $50{ }^{\circ} \mathrm{C}$ for $24 \mathrm{~h}$ afforded the heterocoupling product (3) in $62 \%$ yield (entry 1) along with homocoupling products of both partners (4 and 5) in $7 \%$ and $30 \%$ respectively and about $20 \%$ of 1 unreacted. In the same conditions, $\mathrm{NiBr}_{2}$ (dme) associated with 2,2'bipyridine ligand afforded a much lower yield (12\%), highlighting the advantage of developing new cobalt-catalytic systems for cross-electrophile couplings (see Table S1 entry 20).

Table 1. Optimization of the reaction conditions ${ }^{a}$

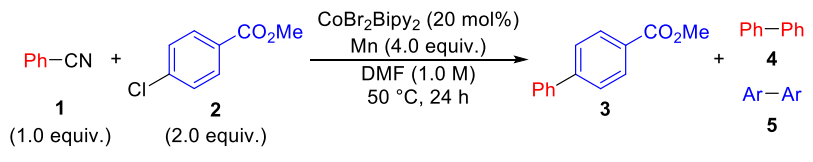

\begin{tabular}{|c|c|c|c|c|}
\hline entry & $\begin{array}{l}\text { deviation from } \\
\text { standard conditions }\end{array}$ & $\begin{array}{l}\text { yield } 3 \\
(\%)^{b}\end{array}$ & $\begin{array}{l}\text { yield } 4 \\
(\%)^{b}\end{array}$ & $\begin{array}{l}\text { yield } \mathbf{5} \\
(\%)^{b, c}\end{array}$ \\
\hline 1 & none & 62 & 7 & 30 \\
\hline 2 & $\begin{array}{l}\mathrm{CoBr}_{2}\left(20 \text { mol\%), } \mathrm{PPh}_{3}\right. \\
(40 \text { mol\%) }\end{array}$ & 5 & 2 & 44 \\
\hline 3 & $\begin{array}{l}\mathrm{CoBr}_{2}(20 \mathrm{~mol} \%) \\
\text { dtbbipy (40 mol\%) }\end{array}$ & 37 & 5 & 34 \\
\hline 4 & $\begin{array}{l}\text { DMF/Pyridine }(10 / 1) \\
\text { instead of DMF }\end{array}$ & 55 & 10 & 34 \\
\hline 5 & $80^{\circ} \mathrm{C}$ instead of $50^{\circ} \mathrm{C}$ & 35 & 6 & 37 \\
\hline 6 & $\begin{array}{l}\mathrm{Me}_{3} \mathrm{SiSiMe}_{3} \text { (1.0 equiv.) } \\
\text { as additive }\end{array}$ & 69 & 10 & 24 \\
\hline 7 & $\begin{array}{l}\mathrm{BPh}_{3}(1.0 \text { equiv.) as } \\
\text { additive }\end{array}$ & 44 & 6 & 28 \\
\hline 8 & $\begin{array}{l}\operatorname{AlMe}_{3}^{d} \text { ( } 1.0 \text { equiv.) as } \\
\text { additive }\end{array}$ & 81 & 9 & 18 \\
\hline 9 & $\begin{array}{l}\mathrm{CoBr}_{2} \mathrm{Bipy}_{2}(10 \mathrm{~mol} \%) \\
\text { and } \mathrm{AlMe}_{3}{ }^{d}(0.5 \text { equiv.) } \\
\text { as additive }\end{array}$ & 79 & 9 & 18 \\
\hline
\end{tabular}

Deviation from entry 9 as new standard conditions

$\begin{array}{lllll}10 & 1.5 \text { equiv. of } \mathrm{Mn} & 81 & 9 & 17 \\ 11 & 1.5 \text { equiv. } \mathrm{ArCl} & 62 & 13 & 16 \\ 12 & \text { Without } \mathrm{CoBr} 2 \mathrm{Bipy}_{2} & 0 & 0 & 0 \\ 13 & \text { Without } \mathrm{Mn} & 9 & 3 & 1\end{array}$

${ }^{a}$ Reaction conditions: benzonitrile 1 ( $1 \mathrm{mmol}, 1.0$ equiv.), methyl 4-chlorobenzoate 2 ( 2 mmol, 2.0 equiv.), CoBr2Bipy2 (20 mol\%), Mn powder (4.0 equiv.), N,N-dimethylformamide (DMF) $(1 \mathrm{M}), 50^{\circ} \mathrm{C}, 24 \mathrm{~h}$. See the SI for full optimization details. ${ }^{b}$ Yield determined by GC using pentadecane as internal standard. 'Yield calculated towards 2. ${ }^{d}$ Solution of AlMe3 (2 M) in toluene. Bipy: 2,2'-bipyridine; dtbbipy: 4,4'-di-tertbutyl-2,2'-bipyridine. 


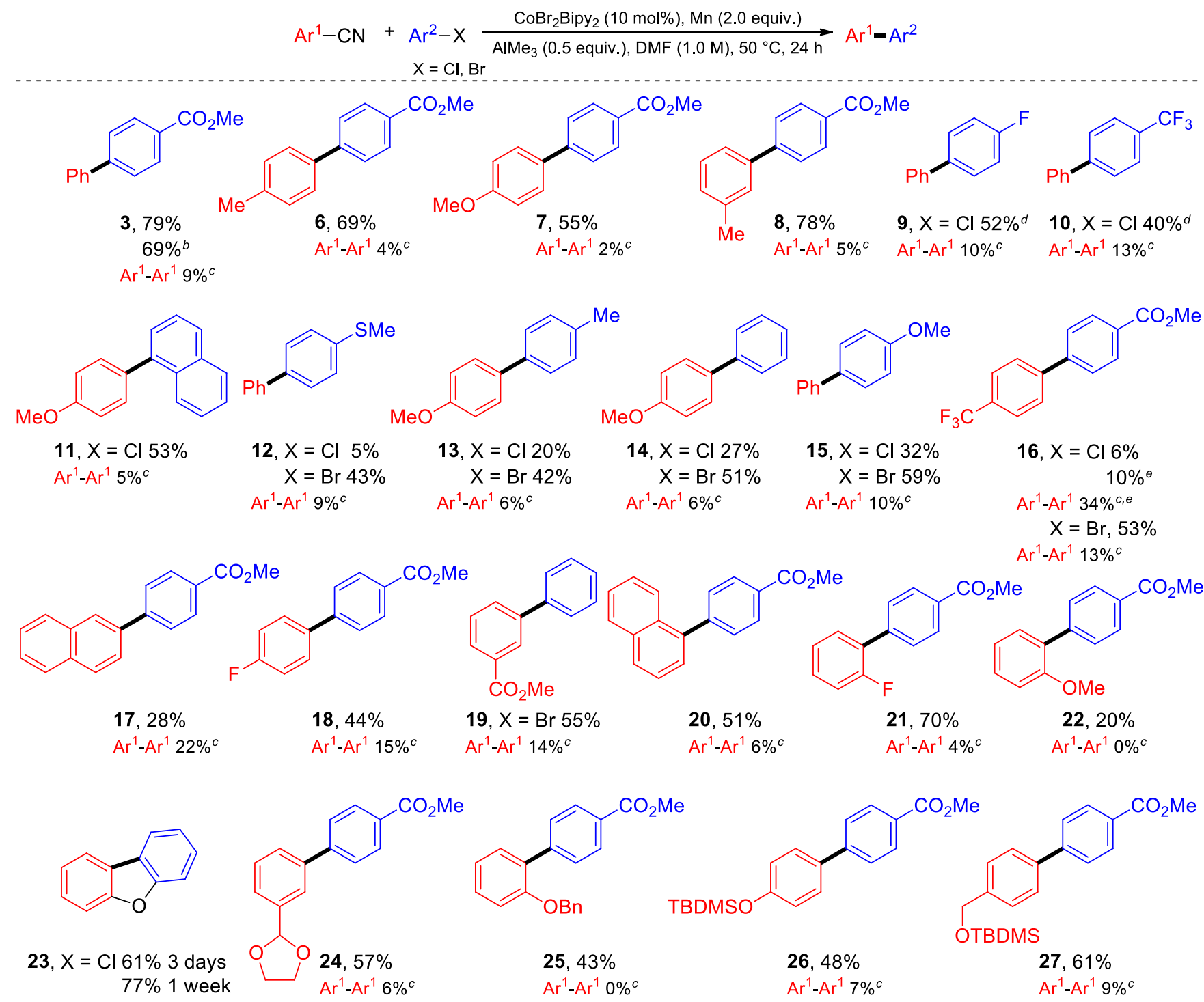

${ }^{a}$ Reactions performed on $1 \mathrm{mmol}$ scale - Isolated yields. $b 10 \mathrm{mmol}$ scale. ${ }^{c} \mathrm{GC}$ yield using n-pentadecane as internal standard. $d \mathrm{NMR}$ yield. $e$ Without AlMe3.

A first screening of different kinds of ligands (see Table S1) showed the great superiority of $N, N$-heterocyclic ones to perform the reaction (entry 2). Changing the simple 2,2'bipyridine ligand for bulkier and electron-richer ones resulted in lower conversion of 1 (entry 3). Interestingly, contrary to many cobalt-catalyzed cross-electrophile couplings reported in $\mathrm{DMF},{ }^{28 \mathrm{~b}, 30}$ pyridine as co-solvent is of no use to improve the transformation (entry 4) leading to an increased formation of $\mathbf{5}$. Whereas elevated temperature is crucial for some methodologies reported to activate $\mathrm{C}-\mathrm{CN}$ bond, ${ }^{19,20,23,25}$ in our case, rising the temperature above $50{ }^{\circ} \mathrm{C}$ showed a detrimental effect (entry 5), with higher amounts of remaining $\mathbf{1}$, and $\mathbf{5}$. To diminish the quite significant amount of $\mathbf{1}$ unreacted, we therefore tried to add some additives (see Table S4).
Indeed, previous reports have shown that the use of additives dramatically facilitated the insertion of transitionmetal catalysts into the $\mathrm{C}\left(s p^{2}\right)-\mathrm{CN}$ bond of benzonitrile derivatives, either by assistance ${ }^{16}$ or by acting as Lewis acid to weaken the $\mathrm{C}\left(s p^{2}\right)-\mathrm{CN} .^{31}$ The use of hexamethyldisilane showed only a slight improvement of the yield (entry 6), suggesting its prominent role as Lewis acid than as an assistant to the insertion, like in the method developed by Chatani. ${ }^{20 a, 25}$ Whereas $\mathrm{BPh}_{3}{ }^{19,31 b, c}$ (entry 7) was prejudicial to the reactivity, $\mathrm{AlMe}_{3}{ }^{31 \mathrm{c}, \mathrm{d}}$ displayed the best efficiency to overcome the lack of reactivity of $\mathbf{1}$ (entry 8). The use of $\mathrm{AlMe}_{3}$ not only increased the selectivity (see Figure S1 and S2) towards the formation of $\mathbf{3}$, significantly reducing the amount of 5 to $18 \%$, but also enabled us to maintain high yield with lower catalyst loading (entry 9) and reductant quantity (entry 10 ), actually close to the 
stoichiometry (see Table S6 entry 6). However, a reduced amount of 2 resulted in a lower yield (entry 11), yet still satisfactory in case a high-value halide derivative is used. Finally, no product was detected when cobalt catalyst was removed (entry 12), whereas a small amount of product could be observed without Mn (entry 13). Indeed, $\mathrm{AlMe}_{3}$ might play the role of the reductant but is not adequate to perform the reaction as sole reducing agent (see Table S5 entry 5).

Scope of the reaction. With the optimized conditions in hand, we then investigated the scope of the title transformation (Table 2). The reaction works in accordance with most cross-electrophile couplings catalyzed by cobalt previously reported $d^{5 b, 26,27,30}$ and is highly sensitive to the electronic properties of the substrates, sometimes necessitating tuning of the coupling partners to induce crossselectivity. It should be pointed out that the superior reactivity of aryl iodides compared to aryl cyanides mainly led to the homo-coupling products of the aryl iodide substrates instead of cross-coupling products. For benzonitrile (3) or derivatives bearing moderately electron-donating groups (EDG) $(\mathbf{6}, \mathbf{7}, \mathbf{8})$, the cross-coupling performed smoothly with activated chloroaryl derivatives bearing electron-withdrawing groups (EWG) $(\mathbf{9}, \mathbf{1 0}, \mathbf{1 1})$. Unsurprisingly, when reacted with electron-richer aryl chlorides for which the oxidative addition is less favorable, the benzonitrile derivatives preferably dimerized to give lower yields $(\mathbf{1 2}, \mathbf{1 3}, \mathbf{1 4}, \mathbf{1 5})$. Nevertheless, better selectivities were obtained when using more reactive bromoaryl analogues. In the same way, highly electron-rich benzonitriles showed poor or no reactivity, presumably due to a difficult oxidative addition, even with an increased amount of activating Lewis acid (see S9.2.).

On the contrary, benzonitriles bearing strongly EWG (16) or moderately EWG at an activated position $(\mathbf{1 7}, \mathbf{1 8})$ showed great reactivity but preferentially dimerized, leading to lower yield when reacted with chloroaryl derivatives under standard reaction conditions. While removing $\mathrm{AlMe}_{3}$ proved not sufficient enough (16), choosing the more reactive bromoaryl counterpart as coupling partner usually afforded the cross-coupled product in good yields $(16,19)$. As for benzonitriles bearing moderately EWG $(20,21)$, the cross-coupling performed easily with an activated arylchloride partner in good to very good yields.

Steric hindrance, such as methyl group in ortho-position of any of the coupling partners, was not well tolerated due to favored dimerization of the other unhindered partner (see S9.2). Unlike its homolog in para-position, 2methoxybenzonitrile afforded 2-hydroxybenzonitrile as major product, coming from the deprotection of the starting material mediated by $\mathrm{AlMe}_{3}$ (22).32 This deprotection is thus promoted by the proximity of $\mathrm{AlMe}_{3}$ to the methoxy group, clearly indicating its chelation to the nitrile moiety in order to activate it. However, when no side reactions are competing, high yields can be reached even though longer reaction times are needed, like in an intramolecular reaction (23). Interestingly, despite the presence of $\mathrm{AlMe}_{3}$, sensitive functional groups like acetals (24), benzyl- (25) and even silyl-protected phenols (26) or alcohols (27) usually gave good yields with only small amounts of deprotected starting material even in ortho-position.

Mechanistic insight. Intrigued by the unusual reactivity of this simple cobalt-based catalytic system towards stable benzonitrile derivatives, we then focused on obtaining some insight into the mechanism of the reaction. ${ }^{33}$ In particular, a plot of the time dependence for the reaction progress for products $\mathbf{3}$ and $\mathbf{5}$ at the beginning of the reaction (see Figure S3) showed two different induction periods for each substrates to be activated, with 2 being reacted faster than 1. This peculiar observation encouraged us to investigate mainly which species could be able to activate both partners.

Above all, we started to study the nature of the catalysis. We envisioned that two types of catalyst could be able to perform such cross-coupling after reduction of the cobalt pre-catalyst by Mn powder. On one hand, homogeneous low-valent cobalt species could be the active catalyst. On the other hand, heterogeneous catalysis might be effective with either cobalt nanoparticles ${ }^{34}$ or a blend of activated cobalt/manganese metals involved. To verify the nature of the catalysis, we submitted a solution of pre-catalyst $\mathrm{CoBr}_{2} \mathrm{Bipy}_{2}$ in DMF to reduction with Mn powder overnight. The resulting dark blue supernatant of reduced species was submitted to the mercury drop test ${ }^{35}$ with coupling partners 1 and $\mathbf{2}$ separately (see S3.2) If heterogeneous cobalt metal catalyst was involved, no reactivity would be observed with $\mathrm{Hg}^{0}$ due to metal poisoning, by amalgamating or adsorbing on the metal surface. Yet, significant amounts of methyl benzoate (9\%) and 5 (13\%) were observed from the reaction of $\mathbf{2}$ with the supernatant, regardless of the presence of $\mathrm{Hg}^{0}$. The reactivity of the remaining activated cobalt/manganese blend was also evaluated with 2 and this time, no reactivity was observed. While these results seem to be consistent with homogeneous catalysis, surprisingly, similar experiments with $\mathbf{1}$ led to no reactivity in all cases (see S3.2), preventing us from drawing any conclusion.

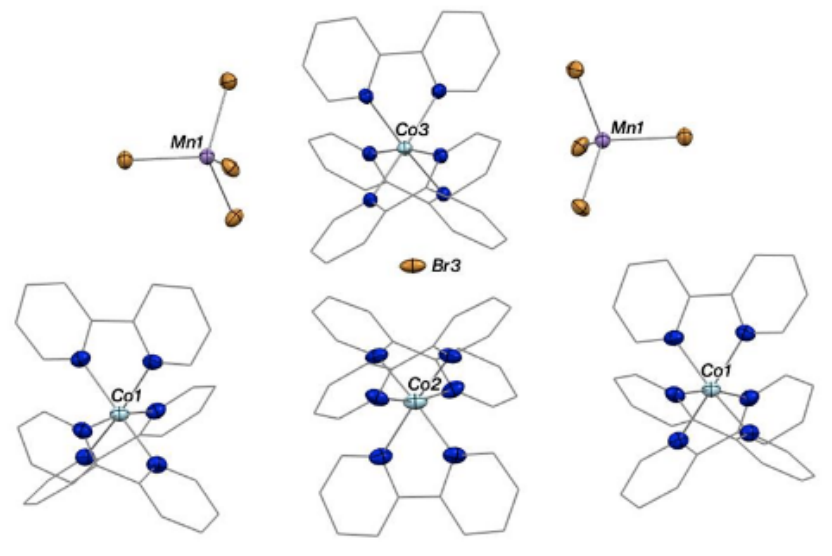

Figure 1. ORTEP of reduced cobalt complex Co-Red [3 [Co ${ }^{\mathrm{I}-}$ Bipy $\left.\left.]^{+} ;{ }^{2} \mathrm{Co}^{I} \mathrm{Bipy}_{3}\right]^{2+} ; 2\left[\mathrm{MnBr}_{4}\right]^{2-} ; \mathrm{Br}^{-}\right]$at $50 \%$ probability ellipsoids with $\mathrm{H}$ atoms and solvent omitted and 2,2'bipyridine ligands in wireframe for clarity. 
Whereas it seems well-established that $\mathrm{Co}^{\mathrm{II}}$ pre-catalysts afford $\mathrm{Co}^{\mathrm{I}}$ species after reduction by $\mathrm{Zn}$ powder, ${ }^{5 b, 36}$ we could not find any report indicating clearly the resulting oxidation state after reduction by $\mathrm{Mn}$ powder. From the previous dark blue solution, crystals of a cobalt reduced species were grown and isolated in 65\% yield (see S4.). The resulting Co-Red species crystalize in $\mathrm{P}_{3} 22$ space group. A grown structure with integer chemical formula is shown in Figure 1. Electroneutrality principle allowed the attribution of oxidation states for each Co atoms with a resulting 3/1 ratio of $\mathrm{Co}^{1} \mathrm{Bipy}_{3} / \mathrm{Co}^{11} \mathrm{Bipy}$. A close look at characteristic bond distances (see Table S9) and comparison with literature values ${ }^{37}$ validated the $3 / 1$ ratio found and indicated a charge repartition mainly centered on the metallic atoms in the solid state of $\mathrm{Co}^{\mathrm{I}}\left(\mathrm{Bipy}^{0}\right)_{3}$ (see S6. for full details on X-Ray structure solving). ${ }^{37}$ Moreover, the XRay structure of Co-Red is consistent with the observation by Anson et al. ${ }^{38}$ that $\mathrm{Co}^{\mathrm{I}}$ complexes of less than three 2,2'bipyridines per cobalt have a high propensity to redistribute their ligands to fill their coordination sites in order to gain stability. Since the ligand redistribution is believed to generate cobalt(0), ${ }^{38,39}$ this led us to propose the following equation for the formation of Co-Red (Equation 1). Besides, this result points out the importance of having investigated the nature of the catalysis. Finally, this process of reduction/ligand redistribution would be in accordance with the induction period previously observed (Figure S3).

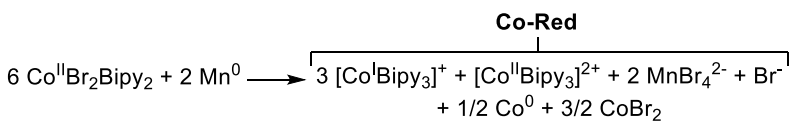

Equation 1. Equation of reduction/ligand redistribution of $\mathrm{CoBr}_{2} \mathrm{Bipy} 2$ by $\mathrm{Mn}$ powder.

We thus performed catalytic experiments in DMF at 50 ${ }^{\circ} \mathrm{C}$ for $12 \mathrm{~h}$ in the presence of Mn (2.0 equiv.), and employing either Co-Red (Scheme 2(i)) or CoBipys.2BF ${ }_{4}^{37}$ (Scheme 2(ii)) as pre-catalyst. Both complexes afforded the same yield of cross-coupled product than $\mathrm{CoBr}_{2} \mathrm{Bipy}_{2}$

Scheme 2. Catalytic reactions in DMF (1.0 M), $50{ }^{\circ} \mathrm{C}, 12$ $h$ with Mn (2.0 equiv.) and (i) Co-Red; (ii) Co-

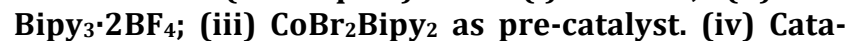
lytic reactions in DMF (1.0 M), $50^{\circ} \mathrm{C}, 12 \mathrm{~h}$ using Co-Red as pre-catalyst without $\mathrm{Mn}^{a}$

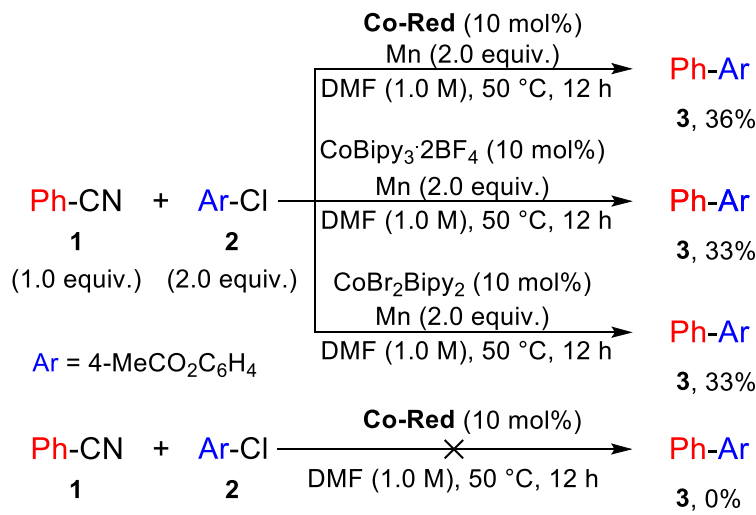

aYields determined by GC using n-pentadecane as internal standard.
(Scheme 2(iii)) in the same conditions, highlighting that complexes of cobalt surrounded by three 2,2'-bipyridine ligands are suitable pre-catalysts for the transformation and the possible involvement of such species as catalytic active species. Interestingly, removal of Mn with Co-Red as pre-catalyst in similar conditions did not lead to any crosscoupling product, indicating the essential role of Mn within the catalytic cycle (Scheme 2(iv)).

We then focused on stoichiometric reactions of Co-Red with 1 and 2 separately (Scheme 3). To our delight, 58\% of 2 was converted into methyl benzoate (ArH 38\%) and dimethyl biphenyl-4,4'-dicarboxylate 5 (Ar-Ar 10\%) confirming Co-Red to be an active species with halogenoaryl derivatives (Scheme 3(i)). ${ }^{40}$ Control stoichiometric experiment with $\mathrm{CoBipy}_{3} \cdot 2 \mathrm{BF}_{4}$ indeed confirmed that only $\mathrm{Co}^{\mathrm{I}}$ species of Co-Red is active towards 2 (see Scheme S11).

In accordance with what has previously been suggested during the mercury drop test (see S3.2), Co-Red did not seem to exhibit any reactivity towards 1 since stoichiometric reaction did not lead to any conversion (Scheme 3(ii)). However, interestingly, precipitation of cobalt complexes of the mixture with toluene and analysis of the toluene supernatant in GC showed appreciable amount of free 2,2'-bipyridine ligand (see Scheme S12). In contrast, the same experiment carried out with $\mathrm{CoBipy}_{3} 2 \mathrm{BF}_{4}$ instead (see Scheme S13) produced only traces amount of free 2,2 '-bipyridine, suggesting that the displacement of the ligand by 1 preferably occurs with the $\mathrm{Co}^{1} \mathrm{Bipy}{ }_{3}$ rather than the $\mathrm{Co}^{\mathrm{II}} \mathrm{Bipy}$ з complex composing Co-Red (Figure 1). Besides, computational data confirmed that the substitution of one 2,2'-bipyridine ligand by one benzonitrile $\mathbf{1}$ is indeed energetically more favorable with $\mathrm{Co}^{\text {IBipys }}$ than Сo" ${ }^{\mathrm{II}} \mathrm{Bipy}_{3}$ (see S.8.1).

Scheme 3. Stoichiometric reactions with Co-Red in DMF (0.1 M), $50^{\circ} \mathrm{C}, 12 \mathrm{~h}$ and (i) 2 . (ii) $1 .^{a}$

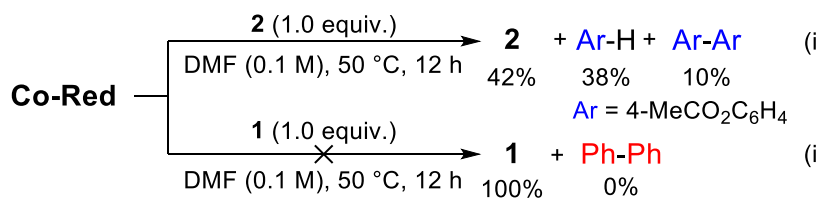

${ }^{a}$ Yields determined by GC using $n$-pentadecane as internal standard.

Concurrently, we performed cyclic voltammetry experiments. To avoid any complexity of the cyclic voltammograms due to the mixture of $\mathrm{Co}^{\mathrm{I} B i p y}{ }_{3} / \mathrm{Co}^{\mathrm{II}} \mathrm{Bipy}{ }_{3}$ of Co-Red, all the experiments were made with the complex $\mathrm{Co}^{\mathrm{I}} \mathrm{Bipy} 3$ generated in situ by reduction of $\mathrm{CoBipy}_{3} \cdot 2 \mathrm{BF}_{4}$ in $\mathrm{DMF}$ by Mn. Figure 2 shows the cyclic voltammograms obtained of $\mathrm{Co}^{1} \mathrm{Bipy}_{3}$ either alone (A) or mixed beforehand with $\mathbf{1}$ in DMF for $12 \mathrm{~h}$ at $50{ }^{\circ} \mathrm{C}$ (B). Cyclic voltammogram of $\mathbf{A}$ revealed a 2-electron reduction wave at $E^{\circ}=-1.55 \mathrm{~V} v s$. SCE, which corresponds to the $\mathrm{Co}^{\mathrm{I}} / \mathrm{Co}^{-\mathrm{I}}$ couple. The partially reversible 1-electron wave at $E_{p}^{o x}=-0.86 \mathrm{~V} v s$. SCE can be assigned to the oxidation of $\mathrm{Co}^{\mathrm{I}}$ into $\mathrm{Co}^{\mathrm{II}}$ species. ${ }^{38}$ By comparison, cyclic voltammogram of $\mathbf{B}$ disclosed a slower 
electron transfer, presenting also a 2-electron reduction wave, but at $E^{\circ}=-1.58 \mathrm{~V} v s$. SCE.

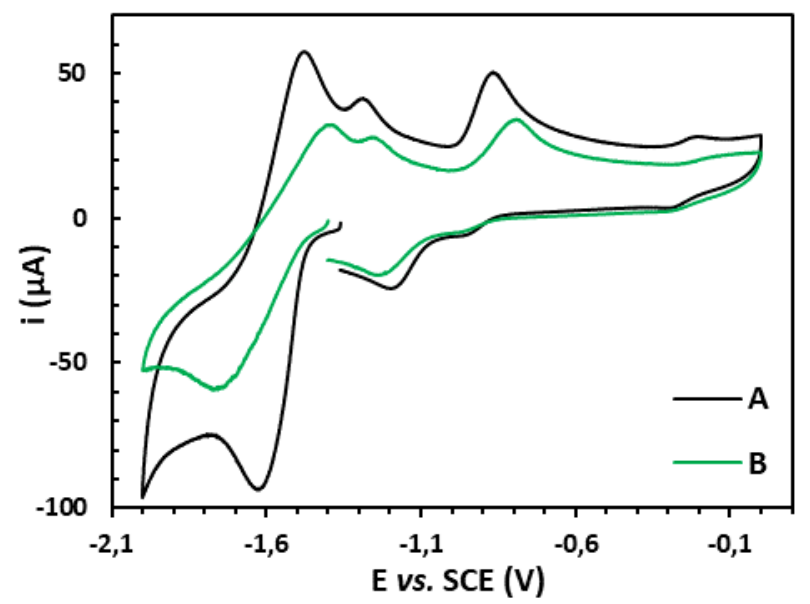

Figure 2. Cyclic voltammograms of $\mathbf{A}$ and $\mathbf{B}$ in DMF. A: $1 \mathrm{mM}$

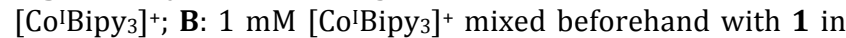
DMF; glassy carbon working electrode; scan rate 1 V.s ${ }^{-1}$. Supporting electrolyte: $100 \mathrm{mM}$ tetrabutylammonium tetrafluoroborate. See SI S.7 for full experiment details.

The combination of this result together with the observation of free 2,2'-bipyridine ligand and DFT calculations, confirmed the formation of a new cobalt species, which could be consistent with [Co $\left.{ }^{\mathrm{B}} \mathrm{Bipy} 2(\mathrm{PhCN})\right]$ (Co1), and could then be possibly reduced by $\mathrm{Mn}$ (see Figure S9). Indeed, even though we observed no clear sign of reactivity following the reduction step in the timescale of cyclic voltammetry ( $5 \mathrm{~V} / \mathrm{s}$ down to $50 \mathrm{mV} / \mathrm{s}$ ), adding $\mathrm{Mn}$ powder to a stoichiometric mixture of Co-Red and $\mathbf{1}$ did lead to the conversion of $41 \%$ of 1 and the formation of biphenyl 4 (Ph-Ph) in $10 \%$ yield after stirring in DMF at $50{ }^{\circ} \mathrm{C}$ for $12 \mathrm{~h}$ (Scheme 4).

Scheme 4. Stoichiometric reactions with Co-Red, 1 and Mn in DMF (0.1 M), $50{ }^{\circ} \mathrm{C}, 12 \mathrm{~h}^{a}$

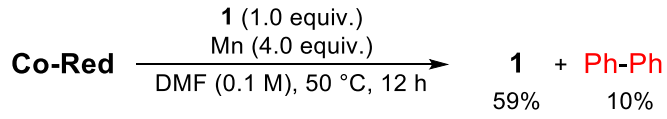

aYields determined by GC using $n$-pentadecane as internal standard.

Therefore, all these results led us to consider an initiation phase comprised of (i) formation of [ $\left.\mathrm{Co}^{\mathrm{B}} \mathrm{Bipy} 2(\mathrm{PhCN})\right]$ Co1, by substitution of one 2,2'-bipyridine of $\mathrm{Co}^{\mathrm{I}} \mathrm{Bipy} 3$ arising from Co-Red, by one benzonitrile and (ii) reduction of the resulting complex by $\mathrm{Mn}$, prior to the insertion into the $\mathrm{C}\left(s p^{2}\right)-\mathrm{CN}$ bond (Scheme 5). Besides, the presence of this initiation phase would be in agreement with the relatively low conversion of $\mathbf{1}$ with Co-Red in the presence of Mn (Scheme 4) and the longer induction period needed to activate $\mathbf{1}$ than $\mathbf{2}$, which has been observed on the plot of the time dependence for the reaction progress (Figure S3). Of note, since the cyclic voltammogram of $\mathbf{B}$ displayed a 2electron reduction wave, we investigated the possible involvement of formal $\mathrm{Co}^{0}(\mathbf{C o 2})$ or formal $\mathrm{Co}^{-\mathrm{I}}(\mathrm{Co3})$ spe- cies for the insertion into the $\mathrm{C}\left(s p^{2}\right)-\mathrm{CN}$ bond of benzonitrile 1.

Scheme 5. Computational data for the involvement of formal cobalt $(0)^{a}$ or cobalt $(-I)^{a}$ species in the initiation phase for the insertion into the $\mathrm{C}\left(s p^{2}\right)-\mathrm{CN}$ bond of 1 .

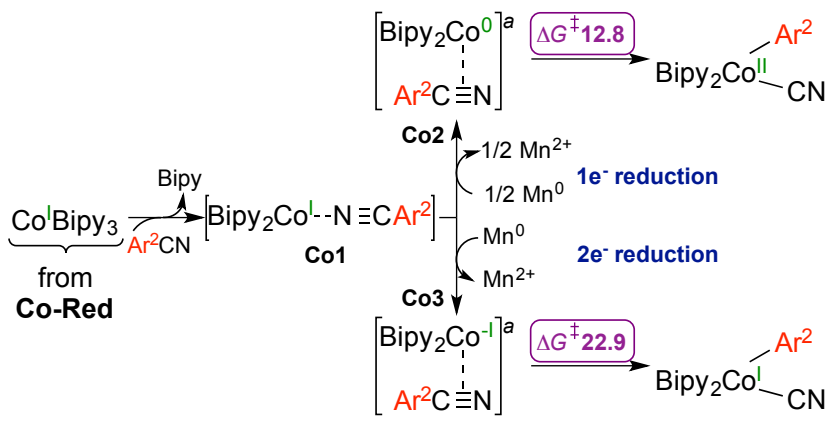

${ }^{a}$ Oxidation states are indicative as it is known that 2,2'bipyridine is a redox non-innocent ligand that can bear the charge repartition.

As showed in Scheme 5, primary DFT calculations suggested that both species could be accounted for the insertion into the $\mathrm{C}\left(s p^{2}\right)-\mathrm{CN}$ bond, but with a quite higher free energy of activation computed for Co3 (22.9 kcal/mol) than for $\mathbf{C o} 2(12.8 \mathrm{kcal} / \mathrm{mol}$ ) (see Schemes S20 and S21 for further details).

As a consequence, we propose the two following catalytic cycles depicted in Scheme 6. In both cases, first, $\mathrm{CoBr}_{2} \mathrm{Bipy}_{2}$ is reduced by $\mathrm{Mn}$ to afford $\mathrm{Co}^{\mathrm{I} B i p y}{ }_{3}$ after ligand redistribution (Equation 1). On one hand, insertion into $\mathrm{C}-\mathrm{Cl}$ bond occurs to give $\mathbf{C o 4}$ (cycles I-A and II-A). On the other hand, substitution of one 2,2'-bipyridine by one benzonitrile leads to the complex Co1, which can then undergo reduction by one electron from Mn to afford complex Co2 (Initiation). This is driven by subsequent insertion into the $\mathrm{C}\left(s p^{2}\right)-\mathrm{CN}$ bond, allowing $\mathrm{Co5}$, with a free energy of activation of $12.8 \mathrm{kcal} / \mathrm{mol}$ when $\mathrm{Ar}^{2}=\mathrm{Ph}$. After that, two different ligand exchanges might take place between complexes Co4 and Co5. Indeed, the two aryl ligands could be carried either by a $\mathrm{Co}^{\mathrm{II}}$ species (Co6) (Scheme 6, I) or a $\mathrm{Co}^{\mathrm{III}}$ species (Co7) (Scheme 6, II), that then, would each ultimately undergo irreversible reductive elimination to afford the biaryl product. These two steps, for one and the other possibilities, were evaluated by DFT calculations with 1 and $\mathbf{2}$ as model substrates. Ligand exchange to form Co6 is endergonic by $9.9 \mathrm{kcal} / \mathrm{mol}$. The following reductive elimination requires $16.4 \mathrm{kcal} / \mathrm{mol}$ of free energy of activation and is exergonic by $18.8 \mathrm{kcal} / \mathrm{mol}$ (see Scheme S18). On the other hand, the exchange to generate Co7 is now exergonic by $8.6 \mathrm{kcal} / \mathrm{mol}$, but the consecutive reductive elimination step necessitates $23.7 \mathrm{kcal} / \mathrm{mol}$ of free energy of activation, which is higher than the one computed in the mechanism I (see Scheme S19). Therefore, even though more experiments would still be needed to fully rule out other mechanistic cycles, all those considerations led us to favor the proposed mechanism I. Finally then, to close the catalytic cycle I, irreversible reductive elimination occurs from $\mathrm{Co}^{\mathrm{II}}$ species $\mathrm{Co} 6$ to afford the biaryl product and 
Scheme 6. Simplified proposed catalytic cycles with $\Delta G^{\ddagger} 323$ of the corresponding insertion/reductive elimination steps (kcal/mol) for $\mathrm{Ar}^{1}=4-\mathrm{MeCO}_{2} \mathrm{C}_{6} \mathrm{H}_{4}$ and $\mathrm{Ar}^{2}=\mathrm{Ph}$, and geometry of the $\mathrm{C}-\mathrm{CN}$ bond activation $\mathrm{TS}$ with selected distances in Å (see S8.2 for full details on DFT calculations). I. Reductive elimination occurs on a cobalt(II) species in cycle B; II. Reductive elimination occurs on a cobalt(III) species in cycle A.

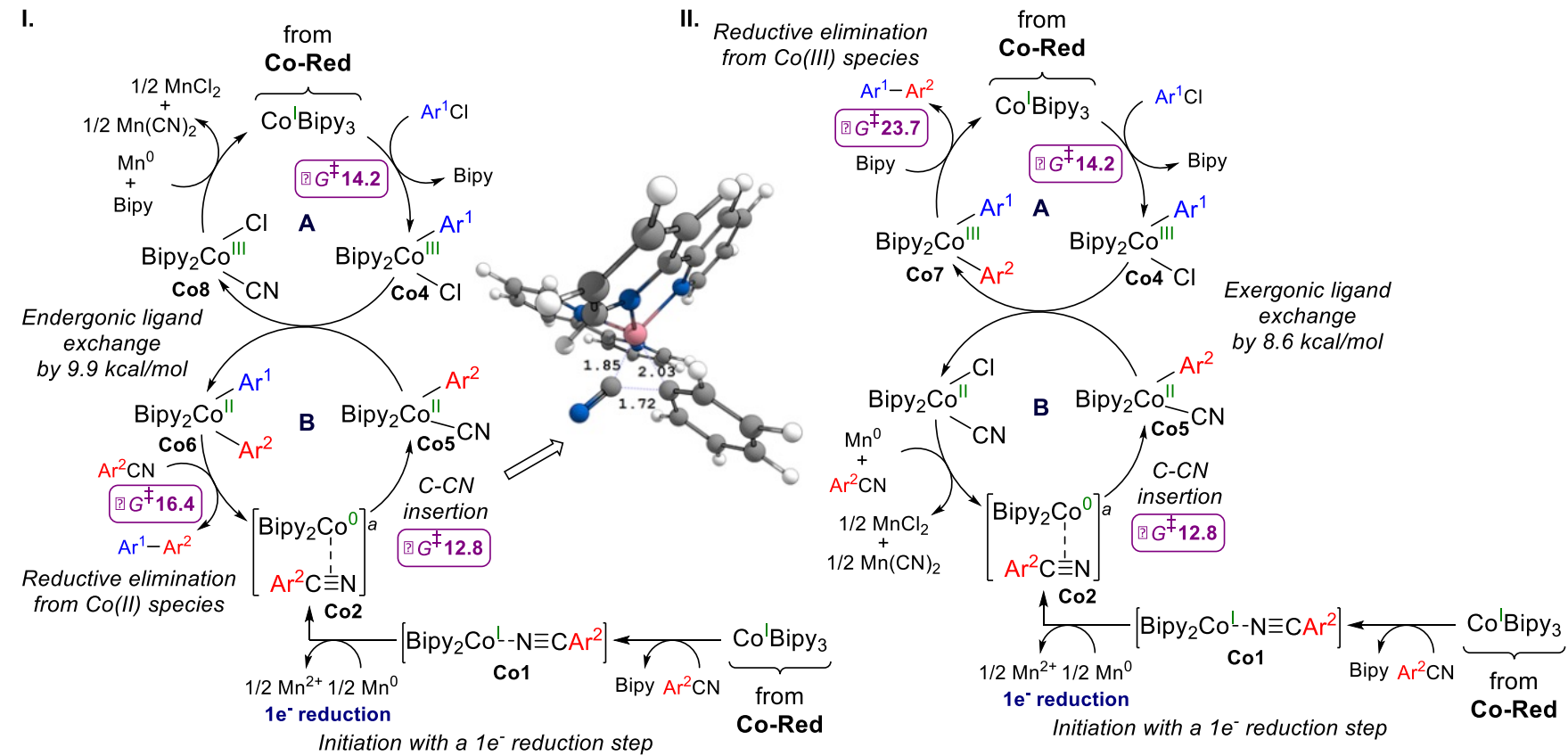

${ }^{a}$ Oxidation state is indicative as it is known that 2,2'-bipyridine is a redox non-innocent ligand that can bear the charge repartition

regenerate formal $\mathrm{Co}^{0}$ species able to activate benzonitrile derivatives again (cycle B), whereas reduction of $\mathbf{C o 8}$ by $\mathrm{Mn}$ and re-coordination of 2,2'-bipyridine ligand regenerates $\mathrm{Co}^{\prime} \mathrm{Bipy}_{3}$ (cycle $\left.\mathbf{I}-\mathbf{A}\right)$.

\section{Conclusion}

In conclusion, we have developed a simple cobaltcatalyzed cross-electrophile coupling between benzonitrile derivatives and aryl halides under mild conditions. The use of $\mathrm{AlMe}_{3}$ Lewis acid boosts the reactivity of benzonitrile derivatives and promotes cross-selectivity without overly affecting functional group tolerance. Furthermore, we believe this work brings major insights into the understanding of this type of reactivity and the mechanism of cobalt-catalyzed cross-electrophile couplings. On one hand, $\mathrm{X}$-Ray structure determination of unusual Co-Red species has revealed an original reduction/ligand redistribution from $\mathrm{CoBr}_{2} \mathrm{Bipy} 2$ pre-catalyst by $\mathrm{Mn}$, which, associated with catalytic and stoichiometric experiments, indicated a $\mathrm{Co}^{\circ} \mathrm{Bipy}_{3}$ active species towards aryl halides. On the other hand, stoichiometric studies combined with cyclic voltammetry experiments suggested the involvement of a new cobalt complex induced by replacement of 2,2 '-bipyridine ligand by benzonitrile derivative. This latter can then be further reduced by 1 or $2 \mathrm{e}^{-}$into formal $\mathrm{Co}^{0}$ or $\mathrm{Co}^{-1}$ species and insert into the $\mathrm{C}\left(s p^{2}\right)-\mathrm{CN}$ bond, which allowed us to propose a mechanism involving two low-valent cobalt complexes of different oxidation states. DFT calculations shed light on the feasibility of the mechanisms with either formal $\mathrm{Co}^{0}$ or $\mathrm{Co}^{-1}$ active species for benzonitrile derivatives, but supported the thermodynamically more favora- ble mechanism with formal $\mathrm{Co}^{0}$ species and subsequent reductive elimination from $\mathrm{Co}^{\mathrm{II}}$ instead of $\mathrm{Co}^{\mathrm{III}}$ species. Work is still ongoing in our laboratory to get a deeper mechanistic insight and a better understanding of the activation of $\mathrm{C}\left(s p^{2}\right)-\mathrm{CN}$ bond by cobalt complexes in order to develop new reactivities.

\section{AUTHOR INFORMATION}

\section{Corresponding Author}

Corinne Gosmini - Laboratoire de Chimie Moléculaire, CNRS UMR 9168, École polytechnique, Institut Polytechnique de Paris, Route de Saclay, 91128 Palaiseau Cedex, France

Email: corinne.gosmini@polytechnique.edu

Vincent Gandon: - Laboratoire de Chimie Moléculaire, CNRS UMR 9168, École polytechnique, Institut Polytechnique de Paris, Route de Saclay, 91128 Palaiseau Cedex, France; Institut de Chimie Moléculaire et des Matériaux d'Orsay (ICMMO), CNRS UMR 8182, Université Paris-Saclay, Bâtiment 420, 91405 Orsay Cedex, France

Email : vincent.gandon@polytechnique.edu

\section{Present Addresses}

Céline Dorval - Laboratoire de Chimie Moléculaire, CNRS UMR 9168, École polytechnique, Institut Polytechnique de Paris, Route de Saclay, 91128 Palaiseau Cedex, France Maxime Tricoire - Laboratoire de Chimie Moléculaire, CNRS UMR 9168, École polytechnique, Institut Polytechnique de Paris, Route de Saclay, 91128 Palaiseau Cedex, France 
Jeanne-Marie Bégouin - Laboratoire de Chimie Moléculaire, CNRS UMR 9168, École polytechnique, Institut Polytechnique de Paris, Route de Saclay, 91128 Palaiseau Cedex, France

\section{Notes}

The authors declare no competing financial interest.

\section{ASSOCIATED CONTENT}

The Supporting Information is available free of charge via the Internet at http://pubs.acs.org.

Reaction optimization tables, mechanistic and stoichiometric studies, synthetic procedures, cyclic voltammetry, DFT calculations and characterization data NMR spectra

$\mathrm{X}$-Ray data for Co-Red

\section{ACKNOWLEDGMENT}

We thank CNRS and École polytechnique for financial support. We used the OCCIGEN computational cluster of the CINES (project A0070810977). We also would like to thank G. Danoun and C. Tard for insightful discussions on this project and A. Pérot for helpful DFT calculations.

\section{REFERENCES}

(1) Johansson Seechurn, C. C. C.; Kitching, M. O.; Colacot, T. J.; Snieckus, V. Palladium-Catalyzed Cross-Coupling: A Historical Contextual Perspective to the 2010 Nobel Prize. Angew. Chem. Int. Ed. 2012, 51, 5062-5085.

(2) A. A. Yaroshevsky, Abundances of Chemical Elements in the Earth's Crust. Geochem. Int. 2006, 44, 48-55.

(3) (a) Nuss, P.; Eckelman, M. J. Life Cycle Assessment of Metals: A Scientific Synthesis. PLOS ONE 2014, 9, e101298. (b) Hunt, A. J.; Matharu, A. S.; King, A. H.; Clark, J. H. The Importance of Elemental Sustainability and Critical Element Recovery. Green Chem. 2015, 17, 1949-1950.

(4) (a) Chirik, P.; Morris, R.; Getting Down to Earth: The Renaissance of Catalysis with Abundant Metals Acc. Chem. Res. 2015, 48, 2495-2495. (b) Non-Noble Metal Catalysis: Molecular Approaches and Reactions; Klein Gebbink, R. J. M., Moret, M.-E., Eds.; WileyVCH: Weinheim, 2018, pp 297.

(5) (a) Biswas, S.; Weix, D. J. Mechanism and Selectivity in Nickel-Catalyzed Cross-Electrophile Coupling of Aryl Halides with Alkyl Halides. J. Am. Chem. Soc. 2013, 135, 16192-16197. (b) Knappke, C. E. I.; Grupe, S.; Gärtner, D.; Corpet, M.; Gosmini, C.; Jacobi von Wangelin, A. Reductive Cross-Coupling Reactions between Two Electrophiles. Chem. Eur. J. 2014, 20, 6828-6842. (c) Everson, D. A.; Weix, D. J. Cross-Electrophile Coupling: Principles of Reactivity and Selectivity. J. Org. Chem. 2014, 79, 4793-4798. (d) Weix, D. J. Methods and Mechanisms for Cross-Electrophile Coupling of Csp2 Halides with Alkyl Electrophiles. Acc. Chem. Res. 2015, 48, 1767-1775.

(6) Selected recent examples: For biaryl formation: (a) Ackerman, L. K. G.; Lovell, M. M.; Weix, D. J. Multimetallic Catalysed Cross-Coupling of Aryl Bromides with Aryl Triflates. Nature 2015 524, 454-457. (b) Kang, K.; Huang, L.; Weix, D. J. Sulfonate Versus Sulfonate: Nickel and Palladium Multimetallic Cross-Electrophile Coupling of Aryl Triflates with Aryl Tosylates. J. Am. Chem. Soc. 2020, 142, 10634-10640. (c) Tang, J.; Liu, L. L.; Yang, S.; Cong, X.; Luo, M.; Zeng, X. Chemoselective Cross-Coupling between Two Different and Unactivated C(aryl)-O Bonds Enabled by Chromium Catalysis. J. Am. Chem. Soc. 2020, 142, 7715-7720. For other types of products: (d) He, R.-D.; Li, C.-L.; Pan, Q.-Q.; Guo, P.; Liu, X.-Y.; Shu, X.-Z. Reductive Coupling between C-N and C-O Electrophiles. J. Am. Chem. Soc. 2019, 141, 12481-12486. (e) Wang, J.; Cary, B. P.;
Beyer, P. D.; Gellman, S. H.; Weix, D. J. Ketones from Nickel-Catalyzed Decarboxylative, Non-Symmetric Cross-Electrophile Coupling of Carboxylic Acid Esters. Angew. Chem. Int. Ed. 2019, 58, 12081-12085. (f) Ni, S.; Li, C.-X.; Mao, Y.; Han, J.; Wang, Y.; Yan, H.; Pan, Y. Ni-Catalyzed Deaminative Cross-Electrophile Coupling of Katritzky Salts with Halides via $\mathrm{C}-\mathrm{N}$ bond Activation. Sci. Adv. 2019, 5, eaaw9516. (g) Wang, J.; Hoerrner, M. E.; Watson, M. P.; Weix, D. J. Nickel-Catalyzed Synthesis of Dialkyl Ketones from the Coupling of N-Alkyl Pyridinium Salts with Activated Carboxylic Acids. Angew. Chem. Int. Ed. 2020, 59, 13484-13489.

(7) Souillart, L.; Cramer, N. Catalytic C-C Bond Activations via Oxidative Addition to Transition Metals. Chem. Rev. 2015, 115, 9410-9464.

(8) For selected recent reviews on strained C-C bonds activation see: (a) Fumagalli, G.; Stanton, S.; Bower, J. F. Recent Methodologies That Exploit C-C Single-Bond Cleavage of Strained Ring Systems by Transition Metal Complexes. Chem. Rev. 2017, 117, 9404-9432. (b) Chen, P.-h.; Billett, B. A.; Tsukamoto, T.; Dong, G. "Cut and Sew" Transformations via Transition-Metal-Catalyzed Carbon-Carbon Bond Activation. ACS Catal. 2017, 7, 1340-1360. (c) Cohen, Y.; Cohen, A.; Marek, I. Creating Stereocenters within Acyclic Systems by C-C Bond Cleavage of Cyclopropanes. Chem. Rev. 2020, doi: 10.1021/acs.chemrev.0c00167. (d) Vicente, R. C-C Bond Cleavages of Cyclopropenes: Operating for Selective RingOpening Reactions. Chem. Rev. 2020, doi: 10.1021/acs.chemrev.0c00151.

(9) For selected unstrained $C-C$ bonds activation see: (a) $C-C$ Bond Activation; Dong, G., Ed.; Top. Curr. Chem., Springer Verlag: Berlin and Heidelberg, 2014, pp 33. (b) Chen, F.; Wang, T.; Jiao, N. Recent Advances in Transition-Metal-Catalyzed Functionalization of Unstrained Carbon-Carbon Bonds. Chem. Rev. 2014, 114, 86138661. (c) Cleavage of Carbon-Carbon Single Bonds by Transition Metals; Murakami, M., Chatani, N., Eds.; Wiley-VCH: Weinheim, 2016, pp 193. d) Nairoukh, Z.; Cormier, M.; Marek, I. Merging C-H and $\mathrm{C}-\mathrm{C}$ bond Cleavage in Organic Synthesis. Nat. Rev. Chem. 2017, 1, 0035. (e) Song, F.; Gou, T.; Wang, B.-Q.; Shi, Z.-J. Catalytic Activations of Unstrained $\mathrm{C}-\mathrm{C}$ Bond Involving Organometallic Intermediates. Chem. Soc. Rev. 2018, 47, 7078-7115. (f) Lutz, M. D. R.; Morandi, B. Metal-Catalyzed Carbon-Carbon Bond Cleavage of Unstrained Alcohols. Chem. Rev. 2020, doi: 10.1021/acs.chemrev.0c00154.

(10) Murakami, M.; Ishida, N. Potential of Metal-Catalyzed C-C Single Bond Cleavage for Organic Synthesis. J. Am. Chem. Soc. 2016, 138, 13759-13769.

(11) (a) Fleming, F. F. Nitrile-Containing Natural Products. Nat. Prod. Rep. 1999, 16, 597. (b) Fleming, F. F.; Yao, L.; Ravikumar, P. C.; Funk, L.; Shook, B. C. Nitrile-Containing Pharmaceuticals: Efficacious Roles of the Nitrile Pharmacophore. J. Med. Chem. 2010, 53, 7902-7917.

(12) Yan, G.; Zhang, Y.; Wang, J. Recent Advances in the Synthesis of Aryl Nitrile Compounds. Adv. Synth. Catal. 2017, 359, 40684105.

(13) Comprehensive Handbook of Chemical Bond Energies; Luo, Y.-R., Boca Raton, CRC Press, 2007, pp 193.

(14) Ruhland, K. Transition-Metal-Mediated Cleavage and Activation of C-C Single Bonds. Eur. J. Org. Chem. 2012, 2012, 26832706.

(15) Selected examples: (a) Garcia, J. J.; Jones, W. D. Reversible Cleavage of Carbon-Carbon Bonds in Benzonitrile Using Nickel(0). Organometallics 2000, 19, 5544-5545. (b) Garcia, J. J.; Brunkan, N. M.; Jones, W. D. Cleavage of Carbon-Carbon Bonds in Aromatic Nitriles Using Nickel(0). J. Am. Chem. Soc. 2002, 124, 9547-9555. (c) Schaub, T.; Döring, C.; Radius, U. Efficient Nickel Mediated Carbon-Carbon Bond Cleavage of Organonitriles. Dalton Trans. 2007, 1993-2002. (d) Ateșin, T. A.; Li, T.; Lachaize, S.; García, J. J.; Jones, W. D. Experimental and Theoretical Examination of C-CN Bond Activation of Benzonitrile Using Zerovalent Nickel. 
Organometallics 2008, 27, 3811-3817. (e) Ohnishi, Y.-Y.; Nakao, Y.; Sato, H.; Nakao, Y.; Hiyama, T.; Sakaki, S. A Theoretical Study of Nickel(0)-Catalyzed Phenylcyanation of Alkynes. Reaction Mechanism and Regioselectivity. Organometallics 2009, 28, 2583-2594. (f) Li, T.; García, J. J.; Brennessel, W. W.; Jones, W. D. C-CN Bond Activation of Aromatic Nitriles and Fluxionality of the $\eta^{2}$-Arene Intermediates: Experimental and Theoretical Investigations. Organometallics 2010, 29, 2430-2445. (g) Munjanja, L.; TorresLópez, C.; Brennessel, W. W.; Jones, W. D. C-CN Bond Cleavage Using Palladium Supported by a Dippe Ligand. Organometallics 2016, 35, 2010-2013. (h) García-Ventura, I.; Flores-Alamo, M.; García, J. J. Carbon-Carbon vs. Carbon-Oxygen Bond Activation in 2- and 3-Furonitriles with Nickel. RSC Adv. 2016, 6, 101259101266.

(16) Selected examples: (a) Klei, S. R.; Tilley, T. D.; Bergman, R. G. Stoichiometric and Catalytic Behavior of Cationic Silyl and Silylene Complexes. Organometallics 2002, 21, 4648-4661. (b) Taw, F. L.; White, P. S.; Bergman, R. G.; Brookhart, M. Carbon-Carbon Bond Activation of $\mathrm{R}-\mathrm{CN}\left(\mathrm{R}=\mathrm{Me}, \mathrm{Ar}\right.$, $\left.{ }^{\mathrm{P} r} \mathrm{r}, \mathrm{Bu}\right)$ Using a Cationic Rh(III) Complex. J. Am. Chem. Soc. 2002, 124, 4192-4193. (c) Taw, F. L.; Mueller, A. H.; Bergman, R. G.; Brookhart, M. A Mechanistic Investigation of the Carbon-Carbon Bond Cleavage of Aryl and Alkyl Cyanides Using a Cationic Rh(III) Silyl Complex. J. Am. Chem. Soc. 2003, 125, 9808-9813. (d) Nakazawa, H.; Kawasaki, T.; Miyoshi, K.; Suresh, C. H.; Koga, N. C-C Bond Cleavage of Acetonitrile by a Carbonyl Iron Complex with a Silyl Ligand. Organometallics 2004, 23, 117-126. (e) Hashimoto, H.; Matsuda, A.; Tobita, H. Reactions of a Silyl(silylene)iron Complex with Nitriles: Carbon-Carbon Bond Cleavage of Nitriles by the Transiently Generated Disilanyliron(II) Intermediate. Organometallics 2006, 25, 472-476. (f) Zhang, S.-L.; Huang, L.; Bie, W.-F. Mechanism for Activation of the C-CN Bond of Nitriles by a Cationic CpRh ${ }^{\text {III }}-$ Silyl Complex: A Systematic DFT Study. Organometallics 2014, 33, 3030-3039. (g) Ueda, Y.; Tsujimoto, N.; Yurino, T.; Tsurugi, H.; Mashima, K. Nickel-Catalyzed Cyanation of Aryl Halides and Triflates using Acetonitrile via $\mathrm{C}-\mathrm{CN}$ Bond Cleavage Assisted by 1,4Bis(Trimethylsilyl)-2,3,5,6-tetramethyl-1,4-dihydropyrazine.

Chem. Sci. 2019, 10, 994-999. (h) Wierschen, A. L.; Lowe, J.; Romano, N.; Lee, S. J.; Gagné, M. R. Silylpalladium Cations Enable the Cleavage of Nitrile C-CN Bonds. Organometallics 2020, 39, 12581268 and references therein.

With boron agents see: (i) Jiang, Y.-Y.; Yu, H.-Z.; Fu, Y. Mechanistic Study of Borylation of Nitriles Catalyzed by Rh-B and Ir-B Complexes via C-CN Bond Activation. Organometallics 2013, 32, 926-936. (j) Kinuta, H.; Takahashi, H.; Tobisu, M.; Mori, S.; Chatani, N. Theoretical Studies of Rhodium-Catalyzed Borylation of Nitriles through Cleavage of Carbon-Cyano Bonds. Bull. Chem. Soc. Jpn. 2014, 87, 655-669. (k) Esteruelas, M. A.; Oliván, M.; Vélez, A. Conclusive Evidence on the Mechanism of the Rhodium-Mediated Decyanative Borylation. J. Am. Chem. Soc. 2015, 137, 1232112329.

(17) (a) Tobisu, M.; Chatani, N. Catalytic Reactions Involving the Cleavage of Carbon-Cyano and Carbon-Carbon Triple Bonds. Chem. Soc. Rev. 2008, 37, 300-307. (b) Wang, R.; Falck, J. R. Transformations of X (C, O, N)-CN bonds: Cases of Selective X (C, O, N)C Activation. RSC Adv. 2014, 4, 1062-1066. (c) Wen, Q.; Lu, P.; Wang, Y. Recent Advances in Transition-Metal-Catalyzed C-CN Bond Activations. RSC Adv. 2014, 4, 47806-47826. (d) Mattalia, J.M.R. The Reductive Decyanation Reaction: an Overview and Recent Developments. Beilstein J. Org. Chem. 2017, 13, 267-284. (e) Peng, L.; Hu, Z.; Wang, H.; Wu, L.; Jiao, Y.; Tang, Z.; Xu, X. Direct Cyanation, Hydrocyanation, Dicyanation and Cyanofunctionalization of Alkynes. RSC Adv. 2020, 10, 10232-10244.

(18) For metal-free cross-coupling reaction: Quinio, P.; Roman, D. S.; León, T.; William, S.; Karaghiosoff, K.; Knochel, P. TransitionMetal-Free Cross-Coupling of Aryl and $N$-Heteroaryl Cyanides with Benzylic Zinc Reagents. Org. Lett. 2015, 17, 4396-4399.
(19) Hanson, M. G.; Olson, N. M.; Yi, Z.; Wilson, G.; Kalyani, D. Nickel-Catalyzed Coupling of Azoles with Aromatic Nitriles. Org. Lett. 2017, 19, 4271-4274.

(20) For examples of Heck-type coupling: (a) Kita, Y.; Tobisu, M.; Chatani, N. Rhodium-Catalyzed Alkenylation of Nitriles via Silicon-Assisted C-CN Bond Cleavage. Org. Lett. 2010, 12, 18641867. (b) Fang, X.; Yu, P.; Prina Cerai, G.; Morandi, B. Unlocking Mizoroki-Heck-Type Reactions of Aryl Cyanides Using Transfer Hydrocyanation as a Turnover-Enabling Step. Chem. Eur. J. 2016, 22, 15629-15633.

(21) Miller, J. A. C-C Bond Activation with Selective Functionalization: Preparation of Unsymmetrical Biaryls from Benzonitriles. Tetrahedron Lett. 2001, 42, 6991-6993.

(22) With alkenyl and alkyl Grignard reagents: (a) Miller, J. A.; Dankwardt, J. W. Nickel Catalyzed Cross-Coupling of Modified Alkyl and Alkenyl Grignard Reagents with Aryl- and Heteroaryl Nitriles: Activation of the C-CN Bond. Tetrahedron Lett. 2003, 44, 1907-1910; With alkynylzinc reagents: (b) Penney, J. M.; Miller, J. A. Alkynylation of Benzonitriles via Nickel Catalysed C-C Bond Activation. Tetrahedron Lett. 2004, 45, 4989-4992.

(23) Yu, D.-G.; Yu, M.; Guan, B.-T.; Li, B.-J.; Zheng, Y.; Wu, Z.-H.; Shi, Z.-J Carbon-Carbon Formation via Ni-Catalyzed Suzuki-Miyaura Coupling through C-CN Bond Cleavage of Aryl Nitrile. Org. Lett. 2009, 11, 3374-3377.

(24) Liu, N.; Wang, Z.-X. Nickel-Catalyzed Cross-Coupling of Arene- or Heteroarenecarbonitriles with Aryl- or Heteroarylmanganese Reagents through C-CN Bond Activation. Adv. Synth. Catal. 2012, 354, 1641-1645.

(25) Tobisu, M.; Kita, Y.; Ano, Y.; Chatani, N. Rhodium-Catalyzed Silylation and Intramolecular Arylation of Nitriles via the SiliconAssisted Cleavage of Carbon-Cyano Bonds. J. Am. Chem. Soc. 2008, 130, 15982-15989.

(26) Dorval, C.; Gosmini C. in Cobalt Catalysis in Organic Synthesis; Hapke, M., Hilt, G., Eds.; Wiley-VCH: Weinheim, 2020, $163-$ 205.

(27) Recent examples from C-Halogen bond activation: (a) Cai, Y.; Qian, X.; Gosmini, C. Cobalt-Catalyzed Csp $p^{3}-\mathrm{C} p^{3}$ Homocoupling. Adv. Synth. Catal. 2016, 358, 2427-2430. (b) Pal, S.; Chowdhury, S.; Rozwadowski, E.; Auffrant, A.; Gosmini, C. Cobalt-Catalyzed Reductive Cross-Coupling Between Benzyl Chlorides and Aryl Halides. Adv. Synth. Catal. 2016, 358, 2431-2435. (c) Cai, Y.; Benischke, A. D.; Knochel, P.; Gosmini, C. Cobalt-Catalyzed Reductive Cross-Coupling Between Styryl and Benzyl Halides. Chem. Eur. J. 2017, 23, 250-253.

(28) Selected examples from other types of bonds than CHalogen bond activation: in cross-electrophile coupling: (a) Ackerman, L. K. G.; Anka-Lufford, L. L.; Naodovic, M.; Weix, D. J. Cobalt Co-Catalysis for Cross-Electrophile Coupling: Diarylmethanes from Benzyl Mesylates and Aryl Halides. Chem. Sci. 2015, 6, 1115-1119. (b) Bourne-Branchu, Y.; Gosmini, C.; Danoun, G. Cobalt-Catalyzed Esterification of Amides. Chem. Eur. J. 2017, 23, 10043-10047. (c) Reddy, B. R. P.; Chowdhury, S.; Auffrant, A.; Gosmini, C. Cobalt-Catalyzed Formation of Functionalized Diarylmethanes from Benzylmesylates and Aryl Halides. Adv. Synth. Catal. 2018, 360, 3026-3029; in other types of coupling: (d) Korn, T. J.; Schade, M. A.; Wirth, S.; Knochel, P. Cobalt(II)-Catalyzed Cross-Coupling between Polyfunctional Arylcopper Reagents and Aryl Fluorides or Tosylates. Org. Lett. 2006, 8, 725-728. (e) Begouin, J.-M.; Rivard, M.; Gosmini, C. Cobalt-Catalyzed C-SMe Bond Activation of Heteroaromatic Thioethers. Chem. Commun. 2010, 46, 5972-5974. (f) Song, W.; Ackermann, L. Cobalt-Catalyzed Direct Arylation and Benzylation by $\mathrm{C}-\mathrm{H} / \mathrm{C}-\mathrm{O}$ Cleavage with Sulfamates, Carbamates, and Phosphates. Angew. Chem. Int. Ed. 2012, 51, 8251-8254. (g) Zhu, Z.; Li, X.; Chen, S.;. Chen, P.-H.; Billett, B. A.; Huang, Z.; Dong, G. Cobalt-Catalyzed Intramolecular Alkyne/Benzocyclobutenone Coupling: C-C Bond Cleavage via a Tetrahedral Dicobalt Intermediate. ACS Catal. 
2018, 8, 845-849. (h) Liu, X.-G.; Zhou, C.-J.; Lin, E.; Han, X.-L.; Zhang, S.-S.; Li, Q.; Wang, H. Decarboxylative Negishi Coupling of Redox-Active Aliphatic Esters by Cobalt Catalysis. Angew. Chem. Int. Ed. 2018, 57, 13096-13100. (i) Dorval, C.; Dubois, E.; BourneBranchu, Y.; Gosmini, C.; Danoun, G. Sequential Organozinc Formation and Negishi Cross-Coupling of Amides Catalysed by Cobalt Salt. Adv. Synth. Catal. 2019, 361, 1777-1780. (j) Zhang, X.; McNally, A. Cobalt-Catalyzed Alkylation of Drug-Like Molecules and Pharmaceuticals Using Heterocyclic Phosphonium Salts. ACS Catal. 2019, 9, 4862-4866.

(29) For stoichiometric activation: (a) Li, X.; Sun, H.; Yu, F.; Flörke, U.; Klein, H.-F. C-F Bond Cleavage and Unexpected C-CN Activation by Cobalt Compounds Supported with Phosphine Ligands. Organometallics 2006, 25, 4695-4697. (b) Xu, H.; Williard, P. G.; Bernskoetter, W. H. C-CN Bond Activation of Acetonitrile using Cobalt(I). Organometallics 2012, 31, 1588-1590.

(30) In particular: (a) Amatore, M.; Gosmini, C. Efficient Cobalt-Catalyzed Formation of Unsymmetrical Biaryl Compounds and Its Application in the Synthesis of a Sartan Intermediate. Angew. Chem. Int. Ed. 2008, 47, 2089-2092. (b) Qian, X.; Auffrant, A.; Felouat, A.; Gosmini, C. Cobalt-Catalyzed Reductive Allylation of Alkyl Halides with Allylic Acetates or Carbonates. Angew. Chem. Int. Ed. 2011, 50, 10402-10405.

(31) For a review see: (a) Becica, J.; Dobereiner, G. E. The Roles of Lewis Acidic Additives in Organotransition Metal Catalysis. Org. Biomol. Chem. 2019, 17, 2055-2069; For selected examples: (b) Brunkan, N. M.; Brestensky, D. M.; Jones, W. D. Kinetics, Thermodynamics, and Effect of $\mathrm{BPh}_{3}$ on Competitive $\mathrm{C}-\mathrm{C}$ and $\mathrm{C}-\mathrm{H}$ Bond Activation Reactions in the Interconversion of Allyl Cyanide by [Ni(dippe)]. J. Am. Chem. Soc. 2004, 126, 3627-3641. (c) Nakao, Y.; Yada, A.; Ebata, S.; Hiyama, T. A Dramatic Effect of Lewis-Acid Catalysts on Nickel-Catalyzed Carbocyanation of Alkynes. J. Am. Chem. Soc. 2007, 129, 2428-2429. (d) Ni, S.-F.; Yang, T.-L.; Dang, L. Transfer Hydrocyanation by Nickel(0)/Lewis Acid Cooperative Catalysis, Mechanism Investigation, and Computational Prediction of Shuttle Catalysts. Organometallics 2017, 36, 2746-2754.

(32) Du, Z.-T.; Lu, J.; Yu, H.-R.; Xu, Y.; Li, A.-P. A Facile Demethylation of ortho Substituted Aryl Methyl Ethers Promoted by $\mathrm{AlCl}_{3}$.J. Chem. Res. 2010, 34, 222-227 and references therein.

(33) The reaction showed to perform without the help of $\mathrm{AlMe}_{3}$ (Table 1 entry 1) and its role in activating nitriles has been well studied (see ref. (31)), therefore our investigations mainly focused on the cobalt catalyst rather than the role of $\mathrm{AlMe}_{3}$.

(34) Lewis, E. A.; Murphy, C. J.; Pronschinske, A.; Liriano, M. L.; Sykes, E. C. H. Nanoscale Insight into C-C Coupling on Cobalt Nanoparticles. Chem. Commun. 2014, 50, 10035-10037.

(35) (a) Whitesides, G. M.; Hackett, M.; Brainard, R. L.; Lavalleye, J. P. P. M.; Sowinski, A. F.; Izumi, A. N.; Moore, S. S.; Brown, D. W.; Staudt, E. M. Suppression of Unwanted Heterogeneous Platinum(0)-Catalyzed Reactions by Poisoning with Mercury(0) in Systems Involving Competing Homogeneous Reactions of Soluble Organoplatinum Compounds: Thermal Decomposition of Bis(triethylphosphine)-3,3,4,4-tetramethylplatina-cyclopentane. Organometallics 1985, 4, 1819-1830. (b) Widegren, J. A.; Finke, R. G. A Review of the Problem of Distinguishing True Homogeneous Catalysis from Soluble or other Metal-Particle Heterogeneous Catalysis under Reducing Conditions. J. Mol. Catal. A: Chem. 2003, 198, 317-341.

(36) (a) Aresta, M.; Rossi, M.; Sacco, A. Tetrahedral Complexes of Cobalt(I). Inorg. Chim. Acta 1969, 3, 227-231. (b) Gandeepan, P.; Cheng, C.-H. Cobalt Catalysis Involving $\pi$ Components in Organic Synthesis. Acc. Chem. Res. 2015, 48, 1194-1206.

(37) England, J.; Bill, E.; Weyhermüller, T.; Neese, F.; Atanasov, M.; Wieghardt, K. Molecular and Electronic Structures of Homoleptic Six-Coordinate Cobalt(I) Complexes of $2,2^{\prime}: 6^{\prime}, 2^{\prime \prime}$ Terpyridine, 2,2'-Bipyridine, and 1,10-Phenanthroline. An Exper- imental and Computational Study. Inorg. Chem. 2015, 54, 12002 12018 and references therein.

(38) Willett, B. C.; Anson, F. C. Electrochemistry and Adsorption of Bis 2,2'-Bipyridinecobalt(I) and Bis 6,6'-Dimethyl-2,2'-Bipyridinecobalt(I) in Acetonitrile. J. Electrochem. Soc. 1982, 129, 1260 1266.

(39) See also: Hickey, D. P.; Sandford, C.; Rhodes, Z.; Gensch, T.; Fries, L. R.; Sigman, M. S.; Minteer, S. D. Investigating the Role of Ligand Electronics on Stabilizing Electrocatalytically Relevant Low-Valent Co(I) Intermediates. J. Am. Chem. Soc. 2019, 141, 1382-1392.

(40) The remaining of $\mathbf{2}$ might come from catalyst deactivation pathways such as disproportionation of $\mathrm{Co}^{1} \mathrm{Bipy} 3$ into cobalt metal and $\mathrm{Co}{ }^{I I B i p y} y_{3}$ (see ref. (37-39)) and/or comproportionation of $\mathrm{Co}^{\prime} \mathrm{Bipy}_{3}$ and $\mathrm{Co}^{\mathrm{II}} \mathrm{Bipy}_{2}(\mathrm{Ar})(\mathrm{Cl})$, formed after insertion into the $\mathrm{C}-$ $\mathrm{Cl}$ bond, into cobalt(II) complexes. See also: Polleux, L.; Labbé, E.; Buriez, O.; Périchon, J. Co $\mathrm{Co}^{\mathrm{I}-}$ and $\mathrm{Co}^{0}$-Bipyridine Complexes $\mathrm{Ob}$ tained by Reduction of $\mathrm{CoBr}_{2}$ bipy: Electrochemical Behaviour and Investigation of Their Reactions with Aromatic Halides and Vinylic Acetates. Chem. Eur. J. 2005, 11, 4678-4686. 


\section{For Table of Contents Only}

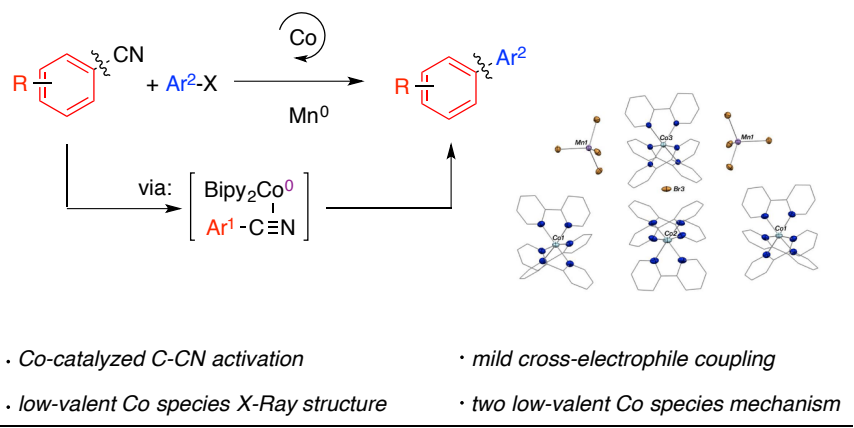

